\title{
Robert VH Dover
}

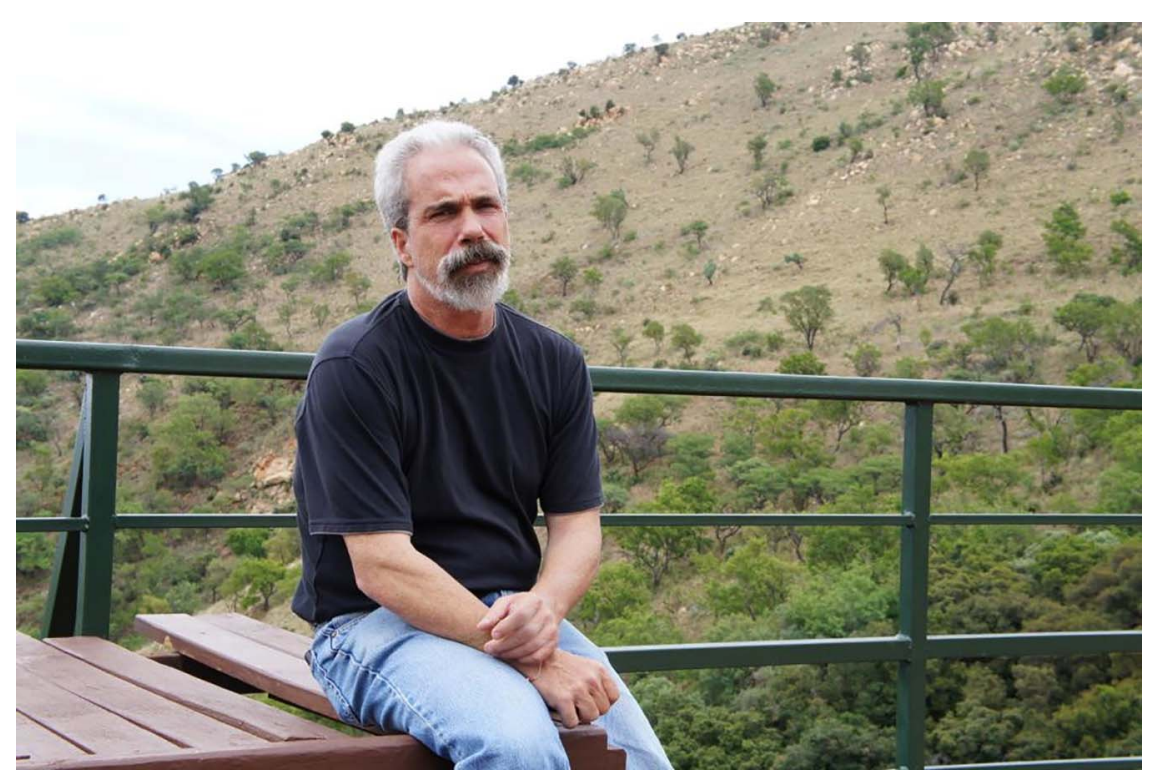

Robert Dover

Source: Claudia Puerta Silva

As the Editors' Note to this inaugural 2019 issue has noted, the Consortium for Comparative Research on Regional Integration and Social Cohesion (RISC approaches this new year with optimism. However, as 2018 came to a close, RISC suffered an immeasurable loss, which we wish to acknowledge here. Professor Robert VH Dover of the Instituto de Estudios Regionales (INER) at the Universidad de Antioquia in Medellín, Colombia, passed away in December, leaving holes in both the consortium's leadership and the hearts of its members. Robert was part of the editorial board of Regions \& Cohesion and the coordinator of RISC's Civil Society, Vulnerable Populations, and State Policies of Health and Well-being working group. This working group promotes collaborative/comparative research on the role and incidence of civil society in regional and state policies of health and well-being. Along with his long-time collaborator Dr. Claudia Puerta Silva (also of INER), Robert was a driving force behind 
the activities of this working group, including panels in RISC's international conferences, workshops and publications. Most prominently, Robert promoted the Healthy Cities initiative within RISC that aimed to foster healthy living in the urban Global South.

Above all, Robert embodied the values and vision that the RISC Consortium strives to attain as an academic community. He was a true intellectual committed to scientific inquiry and one of the most eloquent speakers that we have had the pleasure of knowing. Robert spoke softly, but his words carried significant force. Robert was a dedicated academic, and he never lost sight of the importance of defending human dignity. He combined academic professionalism with a commitment to social solidarity. Robert's enthusiasm was contagious. Although he studied injustices committed in the Global South, he always maintained optimism and hope in his outlook for the world, which significantly enriched our collaborative dialogues. In November 2019, RISC will hold its international conference in Johannesburg, South Africa, and it seems impossible to imagine this meeting without Robert's smiling face, which transmitted solidarity and hope to all those present.

Robert was passionate about two social issues that dominated his research agenda: public health and socio-environmental justice. By chance, the two special sections included in this issue focus on these topics. In presenting these special sections, we honor Robert's memory by highlighting those concerns that were most important to him. We thank Robert for his contributions to RISC's activities, but most importantly, we thank him for having made our collaborations more enjoyable and fulfilling and for his contributions to our collective efforts to strive for a better world. Knowing Robert has made us better people. For this, we are grateful. 